\title{
A socio-ecological model of agency: The role of structure and agency in shaping education and employment transitions in England
}

\author{
Ingrid Schoon \\ i.schoon@ucl.ac.uk \\ Mark Lyons-Amos
}

\author{
UCL Institute of Education, UK, Wissenschaftszentrum, Berlin, Germany
}

London School of Hygiene and Tropical Medicine, UK
(Received February 2016

Revised July 2016)

http://dx.doi.org/10.14301/llcs.v8i1.404

\begin{abstract}
This study examines the role of structural and agentic resources in shaping school-to-work transitions in England. We ask to what extent are young people able to steer the course of their lives despite the constraining forces of social structure, and how satisfied are they with their lives following the completion of compulsory schooling. Drawing on data from the Longitudinal Study of Young People in England we use sequence analysis of monthly activity data to identify differences in the timing and sequencing of education and employment transitions. We identified six distinct pathways, differentiating between an academic track, three pathways involving further education and training, as well as a work-focused transition and a group of young people who were over a long period not in education or training (NEET). The findings suggest that not all young people are inclined to follow an academic track and instead select into pathways involving vocational training or further education, enabling them to experience competence and life satisfaction. For others (about one in 10), however, the lack of socioeconomic and psycho-social resources is too overwhelming and they encounter long-term experience of NEET or are not able to transform their educational credentials into employment opportunities. The findings highlight that in addition to considering structural constraints it is important to conceptualise the role of the agent for a better understanding of variations in youth transitions
\end{abstract}




\section{Introduction}

The transition from school to work is an important developmental task for young people entering the third decade of life, and ranks very high in terms of complexity and relevance for later life outcomes (Buchmann \& Kriesi, 2011; Schulenberg \& Schoon, 2012). There is however still a lack of understanding regarding the distinct pathways young people take when making the transition, the timing and sequencing of events, and the resources available to young people at the start of the $3^{\text {rd }}$ decade. Recent debates have focused on the notion of 'emerging adulthood' (Arnett, 2000) used to describe the generally extended period of education participation and delay in starting paid employment (often until the mid or late 20s). Although, on aggregate, the transition to independent adulthood has been delayed across many Western countries since the 1970s, not all young people participate in higher education. For example, in 2010 the OECD average percentage of 25-34 year olds to have completed tertiary education was just below $40 \%$ (OECD, 2012), and in 2012 the participation rate in higher education among 17 to 30 year olds in the UK was $49 \%$ (BIS, 2013). A large group of young people thus do not go to University. How do they navigate the transition to employment? What is the role of structural and agentic factors in influencing variations in transition pathways? And how do the young people themselves evaluate their lives?

Previous research has shown that the transition to adulthood has been prolonged for those with the socioeconomic resources to invest in their education, leading to a polarisation of life chances (Jones, 2002; McLanahan, 2004). Yet, the assumption of a polarised life course does not take into account the experiences of a 'forgotten middle' (Roberts, 2011), those who do not necessarily go to university and who negotiate their lives by balancing the socioeconomic and psycho-social resources available to them (Schoon, 2015a; Schoon \& LyonsAmos, 2016). Empirical studies testing the complex interplay between individual and structural forces in shaping youth transitions are, however, scarce.

In this study we introduce a socio-ecological model of agency to address the issue of personenvironment interactions. It is argued that to some extent young people are able to steer the course of their lives despite constraining forces of social structure. The socio-ecological approach aims to understand how individuals and social ecologies define each other (Oishi, 2014). It is informed by life course theory with its emphasis on the multiple sources of influence on individual development, ranging from the micro- to the macro context (Elder, 1998; Elder \& Shanahan, 2007), Bandura's social cognitive theory of human action (Bandura, 2001, 2006), and Eccles et al.'s (1993) person-environment fit theory - examing interactions between social structure and agency.

We define social structure as an external, objective force that can influence individual feelings and actions (McLeod \& Lively, 2003), focusing in particular on family socioeconomic resources associated with different social structural positions ${ }^{i}$. We also take into account the wider social context, in particular area characteristics that are understood to shape education and employment opportunities. Individual agency is defined as the capacity to transcend the immediate constraints in one's environment and to shape one's life circumstances and the courses that one's lives take (Bandura, 2001). It is conceptualised as a multi-dimensional construct involving indicators of intentionality, forethought, self-directedness, and self-efficacy. Our socio-ecological model of agency includes the measurement of a. agency across multiple dimensions; b. social structures that affect goal pursuit; c. the wider social contexts that shape transition pathways; and $d$. overall subjective evaluation of one's life. We adopt an explicit developmental approach, taking into account that any point in the life course has to be understood as the consequence of past experiences, and the launch pad of subsequent experiences. We use the model to predict variations in the timing and sequencing of education and employment transitions, following a nationally representative sample of the Longitudinal Study of Young People in England (LSYPE) born in $1989 / 90$ from age 13 to 20 . In our analysis we control for differences in academic ability to focus on the role of agentic processes by which differentiation in transition outcomes occur.

\section{A socio-ecological model of agency}

Life course theory provides a comprehensive framework to integrate assumptions about social structure and individual agency. In life course theory it is argued that all life choices are contingent on the opportunities and constraints of social structure and culture (Elder \& Shananhan, 2007). Moreover, life course theory considers the constraints on human 
development posed by social norms and institutions. Pathways through life are embedded within a larger socio-historical and cultural context, and are shaped by complex interdependent relationships, including links to one's family of origin (Elder, 1998). Some individuals are able to select the path they follow, a phenomenon described as human agency, but these choices are not made in a social vacuum. Individual agency is shaped by opportunity structures, social networks and institutions, and it is argued that individuals often unconsciously reproduce their social structural milieu (Bourdieu \& Passeron, 1977; Giddens, 1991; Hitlin \& Elder, 2007).

Although the concept of agency is a central term in life course theory (Elder, 1998) it has remained an elusive ('slippery') and underspecified theoretical concept (Hitlin \& Elder, 2007). As a non-structural factor agency is not universally accepted or valued in sociological theory (Fuchs, 2001; Loyal \& Barnes, 2001). Yet, there is a growing interest within sociology to render the mainly theoretical notion of agency into a tangible concept for empirical research. In psychology, on the other hand, agency is a central empirical construct in motivational theories, yet mechanisms linking structural factors to action are left largely unexplained (Bandura, 2006).

Recent attempts to reconceptualise agency within life course research draw on the psychological literature of agency (Hitlin \& Elder, 2007; Hitlin \& Johnson, 2015), in particular Bandura's social cognitive theory (Bandura, 2001). Social cognitive theory rejects the duality between individual agency and social structure, and assumes that people create social systems, and these systems, in turn, organise and influence individual lives. Likewise in sociology the reciprocal interactions between social structure and the individual are recognised (Emirbayer \& Mische, 1998). Yet while in psychology interactions between person and social structure are often used to explain the human capacity to shape one's life circumstances and the course of one's life (Eccles, 2008; Heckhausen \& Chang, 2009; Lerner, 1996; Schoon, 2007), in sociology the focus lies on explaining stratification of life course outcomes (Kerckhoff, 2001; Sewell \& Hauser, 1993). There is however overlap in the research interests and a growing body of evidence regarding the interplay between structure and agency from across disciplines. A socio-ecological approach to agency enables us to investigate how objective socioeconomic conditions affect individual thinking, feeling and behaviour, and how different aspects of agency might shape the selection of distinct transition pathways, which can be understood as ecological niches.

\section{Structural influences on agency}

Young people from less privileged backgrounds are leaving education earlier and are less likely to continue in higher education than their more privileged peers, reflecting persistent social inequalities in life chances and opportunities (Erikson \& Jonsson, 1996; Furlong \& Cartmel, 1997; Schoon \& Silbereisen, 2009; Settersten, Furstenberg, \& Rumbaut, 2005). There is also evidence to suggest that children born into less privileged families (characterised by low levels of parental education, low income, unemployment, single or early parenthood, poor housing conditions) show, in general, lower levels of educational attainment (Breen \& Goldthorpe, 2001; Bukodi \& Goldthorpe, 2013; Shavit, Arum, \& Gamoran, 2007), selfconfidence and educational achievement motivation (Duckworth \& Schoon, 2012; Eccles, 2008; Mortimer, 2003; Schoon, 2014). Explanations of these associations refer to cumulative risk effects (DiPrete \& Eirich, 2006), the lack of financial resources, time or energy of parents to invest in the education of their children (Guo \& Harris, 2000), familiarity with the dominant culture, social networks and connections, or access to warm and supportive parenting (Conger, Conger, \& Martin, 2010).

Moving beyond the proximal family context, there is also evidence that the wider social context, indicated for example by area characteristics, can play a significant role in shaping young people's lives. Living in a disadvantaged neighbourhood (characterised by high levels of unemployment, crime, and lack of community resources), especially in urban areas, has been associated with lower levels of achievement orientation and academic attainment (Ainsworth, 2002; Brooks-Gunn, Duncan, \& Aber, 1997; Murry, Berkel, Gaylord-Harden, Copeland-Linder, \& Nation, 2011) , as well as a higher risk of precarious employment transitions, such as prolonged experiences of not being in employment, education or training (NEET) (Schoon, 2014). Explanations of these associations point to the role of institutional resources, security and community services, as well as collective socialisation models, i.e. the monitoring function that adults adopt to 
control and monitor behaviour (Ainsworth, 2002; loannides \& Loury, 2004; Jencks \& Mayer, 1990).

Socioeconomic risks rarely occur in isolation, and are interlinked. For example, family poverty is increasingly concentrated in certain subgroups of the population and in relatively disadvantaged areas (Duncan \& Brooks-Gunn, 1997; Gregg \& Wadsworth, 2001). Moreover, the relationship between any single risk factor and subsequent outcomes tends to be weak, and serious risk emanates from the accumulation of risk factors (Dannefer, 2003; Rutter, 1981; Schoon, 2006). In an increasingly competitive labour market, it is those with multiple disadvantages who are likely to face the greatest difficulties in establishing themselves (Scarpetta, Sonnet, \& Manfredi, 2010). We thus consider the impact of multiple socioeconomic risk factors in order to a. provide a more comprehensive description of the living situation of young people today, and $b$. to more accurately predict and understand developmental outcomes. We focus in particular on the role of parental education and employment status, housing conditions, as well as family structure - all of which reflect the socioeconomic resources that shape everyday experiences (Moore, Vandivere, \& Redd, 2006; Schoon, 2006), and which have shown independent associations with youth transitions (Duckworth \& Schoon, 2012).

\section{Conceptualising agency as a multi-dimensional construct}

Individuals are not passively exposed to influences from the immediate or wider social context. According to the agency principle they are able to shape the context, which in turn shapes them, and agency can potentially compensate for family disadvantage (Elder \& Shanahan, 2007). Agency is conceptualised as a multi-dimensional construct, involving orientations to the past, the present and the future (Bandura, 2001; Emirbayer \& Mische, 1998; Hitlin \& Elder, 2007). It is informed by past behaviour and experience, reflections about one's capabilities within given constraints and opportunities, and orientations to the future (i.e. expression of future projects, goals, and intentions), which imply expectations that actions taken will be successful. For example, Bandura (2001, p. 1) specifies that the capacity to shape the course of one's life depends on "the temporal extension of agency through intentionality and forethought, selfregulation by self-reactive influence, and self- reflectiveness about one's capabilities, quality of functioning and the meaning and purpose of one's life pursuits". Emirbayer and Mische (1998, p. 962) define agency as "informed by the past (in its "irrational" or habitual aspect) but also oriented towards the future (as a "projective" capacity to imagine alternative possibilities) and toward the present (as a "practical-evaluative" capacity to contextualize the past habits and future projects within the contingencies of the moment)."

The notions of forethought and self-efficacy (or mastery) have been used in a study by Hitlin and Johnson (2015) to empirically operationalise agency within a life course approach. They showed that a general measure of future orientation (perceived life chances) and self-reflection, i.e. perception of own capabilities, predict a range of outcomes in young adulthood, i.e. income, financial problems, self-rated health and depressive effect, independent of academic attainment and a range of socioeconomic background factors (parental education, social class, income, family structure, gender and ethnicity). Moreover, they demonstrate that future orientation and mastery are distinct factors showing independent contributions, and that both general (perceived life chances) and specific future orientations (education aspirations) play a role in shaping developmental outcomes, in particular regarding socioeconomic attainment (earnings and financial problems).

The study by Hitlin and Johnson is one of the few to operationalise agency as a multi-dimensional construct, yet it does not take into account the role of intention and self-directedness, which will be included in our model. Intentions reflect plans of action that imply a pro-active commitment to a given purpose or goal. Self-directedness refers to formative influences of agentic processes based on individual preferences and values. Emirbayer and Mische (1998) argue that both the projective and practical-evaluative aspects of agency are grounded in habitual (often unconscious) patterns of action, which are sometimes also referred to as dispositions, competencies, and preferences. These preferences give stability to response tendencies and help to sustain identity. According to Bandura (2001) plans for the future are rooted in a value system and a sense of personal identity (see also (Eccles \& Wigfield, 2002). People do things that give them selfsatisfaction and refrain from actions that give rise to self-dissatisfaction. They regulate their behaviour 
through a set of self-referenced subfunctions, which include self-monitoring and self-guidance via personal standards.

There is ample empirical evidence to confirm the importance of intentions or goal directedness, selfefficacy, forethought, and preferences or values as predictors across a range of outcomes, including socioeconomic attainment (i.e. occupational and social status or income), psychological wellbeing, and health, even after controlling for academic attainment and structural constraints (e.g. Ashby \& Schoon, 2010; Bandura, Barbaranelli, Caprara, \& Pastorelli, 2001; Eccles, 2008; Hitlin \& Johnson, 2015; Schoon, 2008). The role of these psycho-social resources as predictors of transition experiences in combination with socioeconomic constraints is however less well studied. Most previous studies have established positive associations between distinct agentic aspects and later outcomes, yet there is a lack of studies that have comprehensively examined the complex interplay of multiple agentic and structural factors in shaping the transition from school to work, and there is little understanding of the mechanisms linking agency to variations in transition experiences.

\section{The transition from school to work}

The transition from school to work is a rather busy juncture of the life course that involves multiple and inter-related social role changes, including completion of full-time education and entry into paid employment, and making the step into family formation and parenthood (Settersten, 2007). Each of these role transitions brings with it new challenges and opportunities that rank very high in terms of their importance, complexity and relevance for later outcomes (Buchmann \& Kriesi, 2011; Schulenberg \& Schoon, 2012; Shanahan, 2000).

Life course theory emphasises the importance of timing and sequencing of events in determining their meaning and implications (Elder, 1998). It recognises that transitions can have different meanings, antecedents, and consequences depending on when they occur in the life course and how they fit into larger sequences or trajectories. Within a given society, the timing and sequencing of transitions are governed by a set of institutionalised, normative timetables (Elder, 1998) or 'scripts' of life (Buchmann, 1989) that provide models for both role behaviour as well as informal expectations regarding the age and timing of major transitions. Normative, or 'on-time transitions' are 'culturally prepared' by socialisation and institutional arrangements and are understood to be psychologically salutary. Those who are 'off-time,' i.e. too early or too late, are thought to be the target of negative social sanctions and to experience psychological strain (Heckhausen, 1999; Salmela-Aro, 2009). For example, early transitions (such as early school leaving) and problems in establishing oneself in the labour market, have been associated with lower levels of life satisfaction and health (Kins \& Beyers, 2010; Schulenberg, Bryant, \& O'Malley, 2004).

\section{Developmental match and wellbeing}

Yet, each transition can demarcate a turning point that is associated with change for the better or worse. A number of recent studies across different countries found that there is not one normative way to negotiate a successful transition to adulthood (Schoon, 2015a; Schoon \& Lyons-Amos, 2016; Schulenberg \& Schoon, 2012). There is heterogeneity in transition experiences: early transitions do not necessarily have a negative outcome, and protracted pathways to adulthood are not necessarily optimal. According to 'developmental match/mismatch models' (Eccles et al., 1993; Schulenberg et al., 2004), transitions that provide a progressive increase in developmentally appropriate challenges through which young people can experience competence, enable the individual to successfully master the transition. Building on person-environment fit theory (Eccles et al., 1993), the developing individual is conceptualised as being embedded in changing ecological niches, where the match between individual developmental needs and opportunities provided by the context is itself a dynamic process. Individuals actively choose or create opportunities (within given constraints) that provide a better fit to their preferences, selfperceptions and intentions. For example, for a young person not enjoying school or academic study, entry into employment can provide the opportunity to feel valued, to belong, and to make a contribution. If, however, the demands of the developmental transitions are not matched to the capabilities of the individual or if they amplify previous difficulties, then there can be a negative effect on mental health and wellbeing. This can, for example, be the case if a young person from a less privileged background with the desire to make a living without obtaining higher qualifications is not able to establish herself 
in the labour market, or experiences long-term unemployment.

We thus have to know more about how young people themselves evaluate their transition experiences, how this evaluation is influenced through the available socioeconomic and psychosocial resources, and their match to subsequent transition experiences. We therefore assess individuals' subjective evaluation of their lives by age $19 / 20$, and how this is predicted by a. socioeconomic resources and area characteristics; $b$. individual agency factors; and c. variations in transition experiences. Although there is stability in reports of subjective life evaluations over time and across situation, there can be changes as circumstances in life are changing (Diener, Inglehart, \& Tay, 2013). This is especially relevant during the transition from school to work. We thus examine subjective life evaluations before the transitions were made as an additional control variable. In this way we take into account possible selection effects.

\section{Research questions}

This study examines the role of structure and agency in shaping youth transitions. We test assumptions based on the notion of cumulative disadvantage and developmental-personenvironment matching, taking into account main effects and interactions between indicators of structure and agency.

1. According to assumptions of cumulative disadvantage we expect diversity in transition patterns, reflecting structural constraints on life chances and opportunities starting early in life. For example, we expect young people with fewer socioeconomic resources to have lower levels of agency and to leave school earlier than their more privileged peers.

2. According to a socio-ecological model of agency, we expect that individuals select into a distinct developmental niche that corresponds to their intentions, self-perceptions and preferences within given structural constraints. In particular, we test three distinct processes by which agency processes interact with structural constraints. First, following the assumption of cumulative risk we expect that young people from less privileged background report lower level agency and that agency has a stronger impact among relatively privileged young people. Second, according to an independent effects model we assume that agency indicators predict transition outcomes independent of structural constraints, i.e. there is no interaction and both structure and agency have a unique contribution to transition experiences. Third, according to a compensatory, or interactive effect model, we expect that agency has a more beneficial effect for young people with fewer socioeconomic resources. This would imply, for example, that young people from less privileged backgrounds who feel confident about their academic capabilities and who want to stay on in education are more likely to continue in education, at least for a couple years, than their peers in similar socioeconomic circumstances who do not enjoy school, and who do not want to continue in education.

3. How do young people evaluate their lives at the beginning of their third decade? We expect that the closer the match between the realised transition and earlier self-perceptions, preferences and intentions, the higher the level of life satisfaction. According to assumptions of developmental person-environment matching we expect lower levels of life satisfaction where transitions do not meet one's intentions (i.e. the anticipation to attend university is not realised), or where transition experiences amplify previous adversities (i.e. low socioeconomic and low agentic resources).

\section{Method}

\section{Data}

The study is based on data collected for the Longitudinal Study of Young People in England (LSYPE). LSYPE is a panel study of 15,770 young people born between $1^{\text {st }}$ September 1989 and $31^{\text {st }}$ August 1990. Sample members were all young people in school year nine (age 13/14) or equivalent, in England in February 2004 (for more details see https://www.education.gov.uk/ilsype/workspaces/ public/wiki/Welcome).

Annual face-to-face interviews have been conducted with young people and their parents between 2004 and 2010, and linkage is available to other administrative data, such as the National Pupil Database (NPD), which includes national assessments for all children in England. From LSYPE, information from wave 1 to wave 7 of the dataset was used, covering ages $13 / 14$ to $19 / 20$ years. From NPD, a national assessment given at age 11 is used 
as an indicator of previous academic performance, which is understood to shape subsequent indicators of agency and developmental outcomes.

The LSYPE was sampled using a probability proportional to size method, using schools as the primary sampling unit. It was additionally stratified on deprivation levels of those schools, oversampling more deprived schools and oversampling pupils from minority ethnic groups. The initial sample size was 15,770 partial responses (data from young person) and 13,914 full responses (young person and parent) although not all young people provided information for all waves of the survey. The wave 7 sample consisted of all young people who had been interviewed at previous waves and who agreed to be re-contacted. In total 9,791 cases were contacted at wave 7 in 2010.

\section{Analytic sample}

The analytic sample used for this study comprises individuals with information on their family background at age 13/14 and who participated in the last wave 7 at age 19/20, comprising 9,558 individuals (4,825 males and 4,733 females). The sample is largely representative of the original sample, although there is some greater socioeconomic disadvantage among young people who did not continue in the study. Special sample weights, which are calculated and available from the LSYPE website, were applied to account for the study design, differential selection probabilities and nonresponse bias.

\section{Measures}

\section{Agency}

Since our focus is on education to work transitions we used four domain specific indicators, all assessed at age 13/14 (wave 1).

Academic expectations (intention). The young people were asked how likely it is that they will ever apply to go to university to do a degree. Responses were coded on a five-point scale with response options $5=$ =very likely, $4=$ likely, $3=$ do not know, $2=$ not likely, and 1 =not at all likely.

Goal certainty (forethought): The young people were also asked how likely they think it is that if they do apply to go to university that they will get in. Responses were coded on a 5-point scale with response options $5=$ very likely, $4=$ likely, $3=$ do not know, $2=$ not likely, and $1=$ not at all likely.
Academic self-concepts (self-efficacy). Perceived efficacy to master different academic subjects was measured by asking the young people how good they would say they are in math, English, science and Information/Communication/Technology (ICT). Responses were coded on a four-point scale with response options $4=$ very good, $3=$ fairly good, $2=$ not very good, and $1=$ no good at all. The items were summed up to create an index of academic selfefficacy (Bandura et al., 2001). The scale score was zstandardised. A high score indicates high and a low score low levels of efficacy.

School engagement (self-directedness). We used indicators of emotional school engagement as a marker of student's attitudes and values reflecting self-directedness (Fredricks, Blumenfeld, \& Paris, 2004). A scale score was created based on summed answers to five attitudinal questions: I am happy at school; school work is worth doing; I work as hard as I can at school; I am bored in lessons; on the whole I like being at school. The items were measured on a four point Likert scale ranging from strongly agree to strongly disagree. The scale has good internal consistency (alpha $=.73$ ). The summary scale score was z-standardised, and a high score indicates positive school motivation and a low score school disengagement.

\section{Structural factors}

In our assessment of structural factors we focus on a range of socioeconomic resources available to the family at wave 1 :

Parental education. Information on mother's and father's highest educational level were gathered at wave 1 using the National Vocational Qualification (NVQ) levels. For our analysis we identified the highest level of either parent, using the dominance approach (Erikson, 1984). We differentiated parents with relatively low levels of education $(0=$ no qualifications or qualifications up to level 2, equivalent to seven GCSEs at grades $A$ to $C$ ) and those with higher level of education (1= qualifications at level 3 which enables access to University and higher, i.e. degree level qualifications). Gross household income was reported by the main parent. The banded information was dichotomised to differentiate between those in the lowest income group (1=less than $f 10,400$ per annum) against others (0). Parental worklessness was assessed at the household level (not the individual level). This variable was coded as 1 if no parent living in the household was working at 
the time the family was interviewed (comprising those who were looking for work, as well as those who were economically inactive, not looking for work because of health problems, disability, or looking after the family) and 0 if at least one parent was working. Single parent family. This variable is coded as 1 if the young person lives in a single parent family and 0 if two parents are present. Teen parent. This variable is coded 1 if the cohort member was born to a teen mother and 0 otherwise. Home ownership in wave 1 is coded as 1 if the family owns their own home and 0 if they are renting. We created a cumulative socioeconomic risk index by adding up the six dichotomised indicators.

\section{Area characteristics}

The Index of Multiple Deprivation (IMD) was measured at wave 1 to provide a relative measure of deprivation at the small area level across England. The IMD is made up of seven constituent domains comprising income, employment, education, crime, health deprivation and disability; barriers to housing and services deprivation; and living environment deprivation (for more details see http://data.gov.uk/dataset/index-of-multiple-

deprivation ). Areas are ranked from least deprived to most deprived, on an overall composite measure of multiple deprivation. Another source of geographic information is the urban/rural classification in LSYPE, a measure developed by the Department for Environment Food and Rural Affairs (ONS, 2013). Rurality of an area was coded as 0 , contrasting it to urban areas or towns coded as 1 . Information on rurality and multiple area deprivation provide important contextual information regarding the communities that study members are growing up in.

\section{School-work-transitions}

We used monthly activity history data collected as a routine part of survey between ages 16 to 20 (October 2006 and May 2010) comprising information on being in full-time education, employed (part- or full-time), in an apprenticeship or government training, or being out of the labour force (not in education, employment or training (NEET)).

\section{Subjective life evaluations}

At wave 2 (age 14/15) students were asked whether they have been feeling reasonably happy, all things considered. And at wave 7 (age 19/20) they were asked whether they were satisfied with their life so far. Although the items are differently worded, they both tap into general evaluations of one's life. Both items are coded on a five-point response scale indicating low (1) versus high (5) levels of subjective life satisfaction or happiness.

\section{Controls}

Because both agency and transition experiences are shaped by socio-demographic factors and prior academic attainment, we include additional control variables in our model to ensure that the estimated effects of agency do not simply reflect spurious relationships.

The adolescents reported their gender ( $0=$ male) ( $1=$ female) and ethnicity. Ethnicity was coded as (0) white, versus (1) other ethnic groups. Given the ethnic diversity in England, the different ethnic groups were too numerous and the number of each group was too small to examine differences among the groups individually in our model. Academic performance at age 11 was measured using a latent variable comprising maths, english and science scores in national curriculum tests given at the end of Key Stage 2 (i.e., age 11) i.

Statistical analysis

All analyses were carried out using the software package STATA14. We first provide descriptive statistics and correlation tables. To identify patterns in the timing and sequencing of education and employment transitions between 2006 and 2010 (ages 16 to 21) we used sequence analysis. We apply the sequence analysis for Stata ado (Brinzksy-Fay et al. 2006), using the Needleman-Wunsch algorithm to perform optimised matching, with InDel costs set to 0.7 , substitution costs set to 0.5 and identical between states to create a distance matrix to indicate the differences between pairs of sequences. We then use the distance matrix to perform a cluster analysis using hierarchical clustering (Ward's distance clustering) with the number of clusters determined by the Duda-Hart statistic. Multinomial logistic regression analysis is used to determine the influence of structural and agentic factors as predictors of cluster membership. Finally we use stepwise OLS regression to predict life satisfaction at age 19/20. We used multiple imputation (mi impute command in STATA) to check robustness of findings. Given the consistency in findings we report coefficients derived from the full sample without imputation. 
Table 1: Bivariate correlations between predictor variables included in model with means and std ( $n=9558)$

\begin{tabular}{|c|c|c|c|c|c|c|c|c|c|c|c|c|c|c|}
\hline & 1 & 2 & 3 & 4 & 5 & 6 & 7 & 8 & 9 & 10 & 11 & 12 & Mean & Std \\
\hline \multicolumn{15}{|l|}{$\begin{array}{l}\text { Socioeconomic } \\
\text { resources }\end{array}$} \\
\hline 1.Family resources & 1.00 & & & & & & & & & & & & 1.00 & 1.32 \\
\hline $\begin{array}{l}\text { 2. Area deprivation } \\
\text { (IMD) }\end{array}$ & $.44^{*}$ & 1.00 & & & & & & & & & & & 24.38 & 17.67 \\
\hline $\begin{array}{l}\text { 3. Urban/rural } \\
\text { Agency indicators }\end{array}$ & $.12^{*}$ & $.21^{*}$ & 1.00 & & & & & & & & & & .89 & .31 \\
\hline $\begin{array}{l}\text { 4. Expectation to go to } \\
\text { university }\end{array}$ & $-.08 *$ & $-.04 *$ & -.01 & 1.00 & & & & & & & & & 3.73 & 1.34 \\
\hline 5. Goal certainty & $-.08 *$ & -.01 & .01 & $.59 *$ & 1.00 & & & & & & & & 3.87 & .93 \\
\hline $\begin{array}{l}\text { 6. Academic self- } \\
\text { concept }\end{array}$ & $-.02 *$ & $-.03 \#$ & $.03 \#$ & $.30 *$ & $.36^{*}$ & 1.00 & & & & & & & 0.00 & 1.00 \\
\hline $\begin{array}{l}\text { 7. School engagement } \\
\text { Control variables }\end{array}$ & $-.04 *$ & -.01 & .00 & $.19 *$ & $.19 *$ & $.25^{*}$ & 1.00 & & & & & & 0.00 & 1.00 \\
\hline 8. Female & $.02 *$ & .01 & -.01 & $.07 *$ & .02 & $-.11^{*}$ & $.03 \#$ & 1.00 & & & & & .48 & .50 \\
\hline 9. Non-white & $.26^{*}$ & $.34^{*}$ & $.18^{*}$ & $.21^{*}$ & $.16^{*}$ & $.15^{*}$ & $.10^{*}$ & .01 & 1.00 & & & & .30 & .46 \\
\hline $\begin{array}{l}\text { 10. Academic } \\
\text { attainment at } 11 \\
\text { Life satisfaction }\end{array}$ & $-.30 *$ & $-.26^{*}$ & $.07^{*}$ & $.38^{*}$ & $.32 *$ & $.31^{*}$ & $.17^{*}$ & $.06^{*}$ & $-.11 *$ & 1.00 & & & 0.00 & 1.00 \\
\hline $\begin{array}{l}\text { 11. Life satisfaction age } \\
\text { 14/15 (wave } 2 \text { ) }\end{array}$ & .00 & $.02 *$ & $.01^{*}$ & $.03 *$ & $.06^{*}$ & $.07^{*}$ & $.11^{*}$ & $-.12 *$ & .02 & -.00 & 1.00 & & 3.97 & .90 \\
\hline $\begin{array}{l}\text { 12. Life satisfaction age } \\
20 / 21 \text { (wave } 7 \text { ) }\end{array}$ & $-.09 *$ & $.02 *$ & $.01^{*}$ & $.07^{*}$ & $.09 *$ & $.07^{*}$ & $.10 *$ & $.03 \#$ & $-.04 *$ & $.06^{*}$ & $.11^{*}$ & 1.00 & 3.97 & .93 \\
\hline
\end{tabular}

Note: * $p<.001 ; \# p<.01$

Data source: Longitudinal Study of Young People in England ( $n=9558)$ 


\section{Results}

Table 1 gives the bivariate correlations between the indicators of structural and agentic variables used in the model. Family resources and area characteristics are positively correlated suggesting cumulative risk effects, i.e. experiencing one risk factor is likely to bring with it exposure to other risks as well. However, the correlation of $r=.44$ suggests a considerable degree of independence. There are positive correlations between the four indicators of agency, meaning that a young person with higherlevel agency in one dimension is likely to also score high on another dimension. The highest correlation is between educational expectations and goal certainty $(r=.59)$ while none of the other correlations is above .38, which again indicates a considerable degree of independence. There are negative associations between indicators of socioeconomic risks and individual agency factors, suggesting that young people from less privileged background are reporting lower levels of agency. However, the associations are rather small, ranging from $r=-.02$ for academic self-concepts to $r=-.08$ for goal certainty. Associations between family resources and academic attainment are considerably higher $(r=-.30)$.

\section{Transition pathways of a current cohort of young people}

Using sequence analysis we identified six distinct patterns of education and employment transitions between ages 16 to 20 years. Table 2 presents the Duda-Hart stopping rule statistics, where lower $\mathrm{T}$ square values indicate a better fit. The optimum fit in terms of number of clusters is determined by maximising the Je(2)/Je(1), and the lowest Pseudo Tsquare statistic. According to these criteria the sixcluster solution has the best fit to the data (highlighted in bold).

\section{Table 2: Stopping rules for cluster analysis of LSYPE based on Duda-Hart stopping rule}

\begin{tabular}{lll}
\hline Number of clusters & $\mathrm{Je}(2) / \mathrm{Je}(1)$ & Pseudo T-Square \\
\hline 2 & 0.9012 & 271.08 \\
3 & 0.9031 & 84.13 \\
4 & 0.4606 & 1974.18 \\
5 & 0.8938 & 171.13 \\
6 & 0.9996 & 0.36 \\
7 & 0.5986 & 565.89 \\
\hline Data source: Longitudinal Study of Young People in England $(\mathrm{n}=9558)$
\end{tabular}

Cluster compositions are shown in figure 1. Each cluster is presented in panel a-f, where the overall proportion of the cluster in a particular state is denoted on the ordinate, and the progression between October 2006 to May 2010 on the abscissa (45 months). Cluster a represents a pattern where respondents spend extended periods in full-time education beyond compulsory school age. This cluster, which we termed 'higher education', comprises $45.2 \%$ of the respondents. Educational enrolment in this cluster is consistently above $80 \%$, with little evidence of other consistent labour market activity. 


\section{Figure 1: Cluster compositions extracted from LSYPE}

a) Higher education (45.2\%)

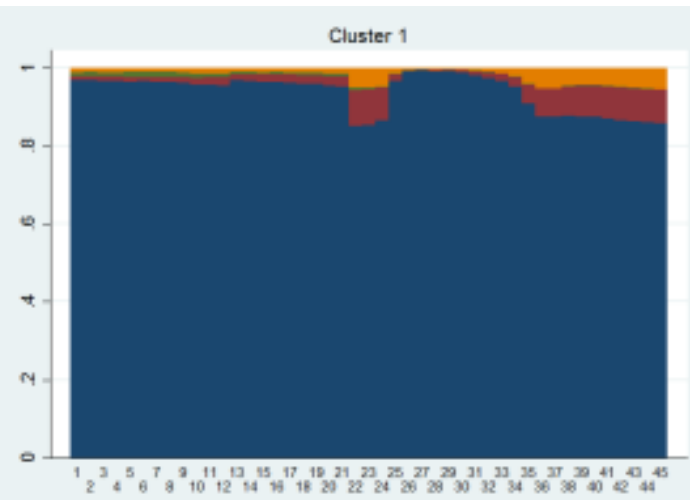

(d) Early work orientation (21.1\%)

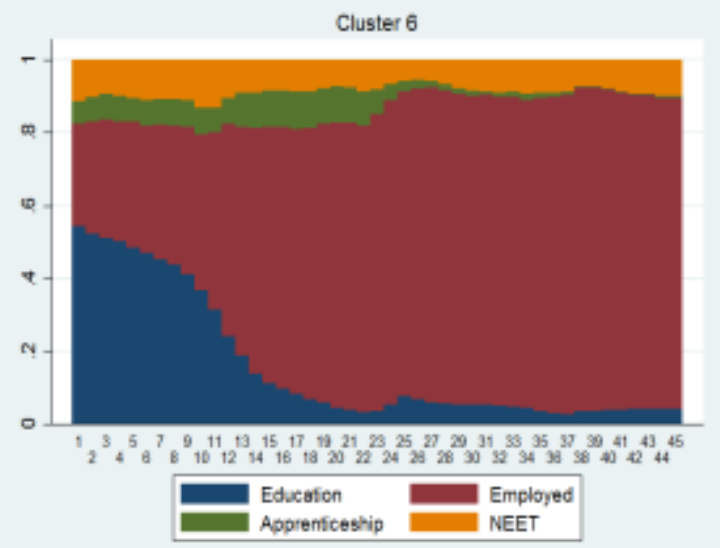

b) Vocational education (6.5\%)

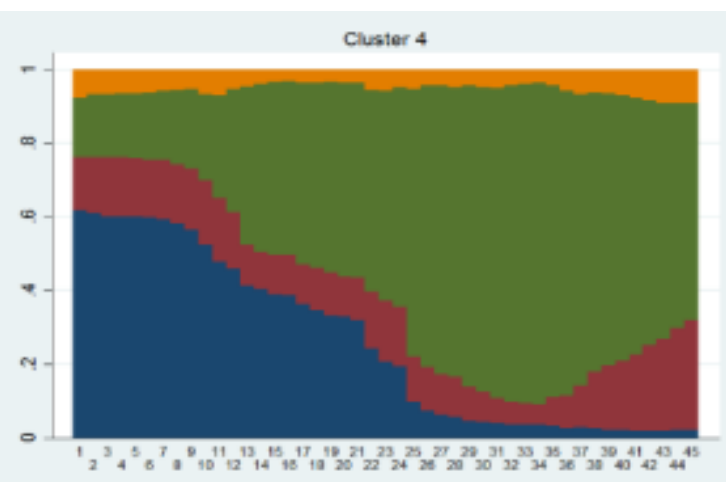

e) NEET after some further education (7.1\%)

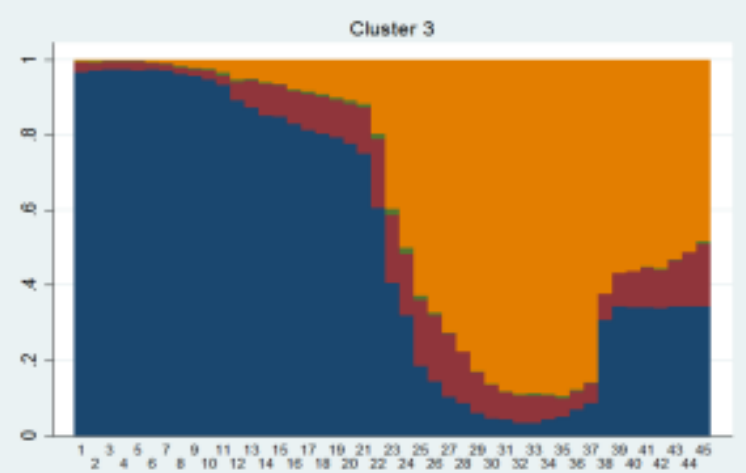

c) Employment after some further education $(14.5 \%)$

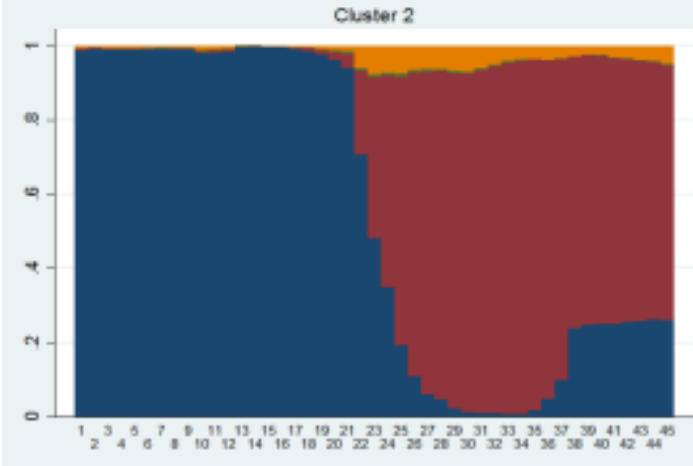

f) Long-term NEET (5.6\%)

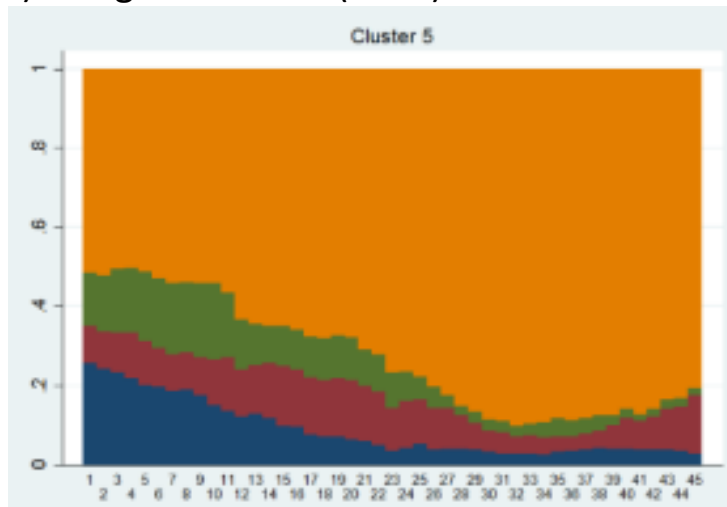

Note: Weighted data. The overall proportion of the cluster in a particular state is denoted on the ordinate, and the progression between October 2006 to May 2010 on the abscissa (45 months). Data source: Longitudinal Study of Young People in England ( $n=9558$ ) 
We identified Cluster $b$ to represent 'vocational training', comprising about $6.5 \%$ of the respondents. Respondents in this cluster gradually transition away from full-time education into labour market orientated activities, including some employment, but largely show an increasing prevalence of vocational training which becomes the modal state, with roughly $90 \%$ of respondents engaged in this activity at age 18. After this there is a gradual upswing in the proportion of respondents in employment as youths transition from training into a full-time job.

Cluster $c$ represents a transition to 'full-time employment after some further education', involving $14.5 \%$ of the cohort. Respondents in this cluster typically remain in education for a limited time before a rapid rise in the proportion of respondents in employment to in excess of $90 \%$. There is a slight increase in the proportion in higher education by age 19, which could however be due to differential censoring in the LSYPE (respondents in higher education are less likely to drop out).

Cluster $d$ represents an early transition into the labour market, or 'early work orientation', capturing $21.1 \%$ of the cohort. In this cluster the proportion of respondents in full-time education falls early (and from a relatively low level) to be replaced by full time employment, which remains the modal state with in excess of $85 \%$ of respondents employed from age 18 onward. There is a relatively small proportion of NEET within this cluster (consistently around 7\%) indicating the relative instability of employment in this cluster (many respondents have short spells out of the labour force).

Cluster e represents a more precarious transition to employment, involving prolonged periods of 'NEET after some further education'. This cluster comprises $7.1 \%$ of the cohort. Around age 18, participation in full-time education falls rapidly (from a relatively high level) among respondents in this cluster. However, in this cluster evidence of full-time employment is rare, and the proportion of respondents being NEET increases rapidly posteducation accounting for more than $90 \%$ of activity at age 18 , with a recovery thereafter.

Cluster $f$ represents an extended 'NEET' experience, comprising $5.6 \%$ of the respondents. NEET comprises more than $50 \%$ of activity at all ages within this cluster, with a movement away from participation in either education or full time work to disengagement. NEET respondents comprise more than $80 \%$ of cluster activity by age $18 / 19$.

\section{Structure and agency as influences on transition experiences}

To assess the association between resources and transition experiences, the cluster membership was treated as a nominal variable. Multinomial logistic (MNL) regression was applied, using the largest cluster (higher education) as the reference group. We also tested interaction effects between socioeconomic risk and the four agency dimensions.

Table 3 gives the estimated relative risk ratios and standard errors of the predictor variables and controls. The clusters used in the multi-nominal regression have very different sample sizes. In relatively small clusters, even large effect sizes might not reach statistical significance. However, even the smallest cluster (the long-term NEET) includes 369 cases. We find, that compared to respondents participating in higher education, young people growing up in families experiencing cumulative socioeconomic risk or who were living in relatively disadvantaged areas were more likely to show an early work orientation, were unemployed after some further education, or NEET. There are also significant associations between area deprivation and participation in vocational training instead of higher education.

Taking into account socioeconomic risk and the control variables included in the model, we find that indicators of agency also play a significant role in predicting transition pathways, suggesting independent effects. Compared to respondents participating in higher education, young people with higher academic aspirations were less likely to be in vocational education, were less likely to be employed after some education, or showed an early work orientation. Those with higher goal certainty were less likely to be in vocational training, NEET after some further education or long-term NEET. Those with high levels of academic self-efficacy were less likely to be in vocational training, employed after some education, showing an early work focus or NEET after some education. Those with high levels of school engagement were less likely to show an early work focus or were long-term NEET. 
Table 3: Predicting transition patterns: Multinominal Regression using Relative Risk Ratios and Std. Error

(Reference Group= Higher Education [ $n=5084]$ )

\begin{tabular}{|c|c|c|c|c|c|c|c|c|c|c|}
\hline $\begin{array}{l}\text { Socio-economic } \\
\text { resources }\end{array}$ & \multicolumn{2}{|c|}{ Vocational Training } & \multicolumn{2}{|c|}{$\begin{array}{l}\text { Employed after some } \\
\text { education }\end{array}$} & \multicolumn{2}{|c|}{$\begin{array}{l}\text { Work-focus } \\
\text { (employed since 16) }\end{array}$} & \multicolumn{2}{|c|}{$\begin{array}{l}\text { Unemployed after } \\
\text { some education }\end{array}$} & \multicolumn{2}{|l|}{ NEET } \\
\hline IMD & $1.015 * *$ & .005 & .996 & .004 & $1.008 \#$ & .003 & $1.013^{*}$ & .005 & $1.020 * *$ & .006 \\
\hline Urban & 1.243 & .335 & .911 & .134 & 1.411 & .247 & 1.367 & .325 & 1.700 & .931 \\
\hline Goal certainty & $.786 \#$ & .078 & .928 & .063 & .950 & .065 & .798\# & .078 & $.687^{*}$ & .097 \\
\hline Self efficacy & $.710 * * *$ & .066 & $.842 * *$ & .048 & $.782 * * *$ & .047 & $.834 \#$ & .072 & 1.012 & .155 \\
\hline $\begin{array}{l}\text { School } \\
\text { engagement }\end{array}$ & .945 & .074 & .947 & .053 & $.862 *$ & .049 & .933 & .0671 & $.655^{* * *}$ & .084 \\
\hline \multicolumn{11}{|l|}{ Controls } \\
\hline $\begin{array}{l}\text { Life satisfaction } \\
\text { at wave } 2\end{array}$ & .885 & .0730 & .950 & .055 & $.861 * *$ & .046 & .922 & .068 & .856 & .098 \\
\hline N (unweighted) & \multicolumn{2}{|c|}{530} & \multicolumn{2}{|c|}{1370} & \multicolumn{2}{|c|}{1515} & \multicolumn{2}{|c|}{690} & \multicolumn{2}{|c|}{369} \\
\hline
\end{tabular}

*** $p<.001 ; * * p<.005 ;{ }^{*} p<.01 ; \# p<.05$

Data source: Longitudinal Study of Young People in England ( $n=9558)$ 
Regarding the control variables we find significant associations between being female and reduced likelihood of entering vocational education, showing an early work orientation, being NEET after some education or long-term NEET (compared to those in higher education). We also find that young people from non-white ethnic backgrounds are more likely to participate in higher education and are less likely in any of the other transition pathways than their white peers. Higher prior academic achievement is associated with a decreased likelihood of entering vocational training, an early work focus or experience of long-term NEET.

Moreover, we find two significant interactions between socioeconomic risk and our indicators of agency. First, the combination of high risk and high goal certainty is associated with a higher likelihood of entering employment after some further education (main effect for family resources: $R R R=.539, p=.104$; main effect for goal certainty: $R R R=.827, p=.015$; interaction effect: $R R R=1.169$, $\mathrm{p}=.011$ ). The finding could indicate that high levels of success expectations are associated with staying on in education, but that socioeconomic or other reasons might then compel the young person to get a job before entering university. Second, high levels of socioeconomic risk in combination with high academic self-efficacy is associated with an increased likelihood of being NEET after some further education (main effect for family resources: $R R R=.543, p=.160$; main effect for self-efficacy: $R R R=.734, p=.004$; interaction effect: $R R R=1.360$, $\mathrm{p}=.028$ ), possibly suggesting a 'dark' side of high selfefficacy beliefs, i.e. that unrealistic self-perceptions might be harmful to individuals, promoting overconfidence and inappropriate persistence.

\section{Who is most satisfied with one's life?}

We ran a stepwise OLS regression to assess the association between structural and agency factors and life satisfaction at age $19 / 20$, as well as the role of transition experiences, treating the cluster membership as a nominal variable. Model 1 includes structural and agency indicators. We find significant associations between life satisfaction and cumulative socioeconomic risk, area deprivation, our indicator of goal certainty and school engagement. Model 2 adds the dummies for the transition clusters. Adding the transition patterns as explanatory variables appears to fully mediate the influence of family socioeconomic risk, yet there remains a significant association between area disadvantage and the two agency indicators. The significant effect of these variables is not removed after adding the control variables to the model. We find independent associations between being female and earlier life evaluation (feeling happy with one's life) for later levels of satisfaction. There were no significant interaction effects between socioeconomic risk and the four agency dimensions. There are no significant differences in levels of life satisfaction between those in higher education, vocational training, and employment after some further education, while those who experienced NEET report the lowest level of life satisfaction. Those with an early work orientation and who experienced unemployment after some further education reported lower levels of life satisfaction then those in higher education. 
Table 4. Predicting life satisfaction (OLS regression)

\begin{tabular}{|c|c|c|c|c|c|c|}
\hline & \multicolumn{2}{|l|}{ Model 1} & \multicolumn{2}{|l|}{ Model 2} & \multicolumn{2}{|l|}{ Model 3} \\
\hline & $\begin{array}{l}\text { Unstandardised } \\
\text { Coefficient }\end{array}$ & Std. Err & $\begin{array}{l}\text { Unstandardised } \\
\text { Coefficient }\end{array}$ & Std. Err & $\begin{array}{l}\text { Unstandardised } \\
\text { Coefficient }\end{array}$ & $\begin{array}{l}\text { Std. } \\
\text { Err }\end{array}$ \\
\hline \multicolumn{7}{|l|}{ Socioeconomic resources } \\
\hline IMD & $-.003 * *$ & .001 & $-.003 *$ & .001 & $-.003^{*}$ & .001 \\
\hline Urban & -.046 & .050 & -.031 & .050 & -.022 & .053 \\
\hline \multicolumn{7}{|l|}{ Agency } \\
\hline Self efficacy & .006 & .016 & .004 & .016 & .019 & .018 \\
\hline School engagement & $.067 * * *$ & .018 & $.053^{* *}$ & .018 & $.045 \#$ & .019 \\
\hline \multicolumn{7}{|c|}{ Transition patterns (ref=Higher Education) } \\
\hline Vocational training & & & .089 & .059 & .115 & .059 \\
\hline Employed after some education & & & -.046 & .036 & -.044 & .038 \\
\hline Work focus employed at 16 & & & $-.152 * * *$ & .044 & $-.140 * *$ & .048 \\
\hline Non-white & & & & & -.069 & .022 \\
\hline Academic attainment at age 11 & & & & & -.018 & .022 \\
\hline Life satisfaction at wave 2 & & & & & $.099 * * *$ & .018 \\
\hline $\mathbf{R}^{2}$ & .025 & & .043 & & .056 & \\
\hline
\end{tabular}

${ }^{* * *} \mathrm{p}<.001 ; * * \mathrm{p}<.005 ;{ }^{*} \mathrm{p}<.01 ; \# \mathrm{p}<.05$; Data source: Longitudinal Study of Young People in England $(\mathrm{n}=9558)$ 


\section{Discussion}

In this paper we present a socio-ecological model of human agency taking into account multiple dimensions of agency, as well as their inter-linkage with social and economic resources in proximal settings as well as the wider social context in shaping the transition from school to work. We show that individuals steer the course of their lives, and actively cope with given structural constraints. In particular, our findings suggest that agency can give rise to the creation of niches that enable the experience of competence and life satisfaction, especially among those who do not follow the academic track. For some however, the lack of socioeconomic and psycho-social resources is too overwhelming and they encounter long-term experience of NEET or are not able to transform their educational credentials into employment opportunities. The findings thus highlight that for a better understanding of variations in youth transitions it is important to consider structural constraints as well as the role of the agent.

The findings illustrate the heterogeneity of transition pathways after completion of compulsory schooling in a current cohort of young people in England. We identified six distinct transition patterns, suggesting that the assumption of polarised transitions is not sufficient to capture the diverse experiences of young people (Schoon, 2015; Schoon \& Lyons-Amos, 2016). In addition to the $45 \%$ of young people who continued in full-time education after compulsory school leaving age, we find that $42 \%$ of the sample succeeded in making the transition into the labour market $(6.5 \%$ who engaged in vocational training, $14.5 \%$ entered employment after some period in further education, $21.1 \%$ showed an early work orientation, entering full-time employment more or less immediately after completing compulsory schooling). However, About $13 \%$ of the sample encountered precarious transitions $(7.1 \%$ experienced NEET after some further education, and $5.6 \%$ encountered long periods of NEET). The findings show that not all young people expect to go to university, that many succeeded in making the transition into employment by age 20 , although some are struggling. Strategies aiming to provide the training and skills needed for the $21^{\text {st }}$ century thus need to provide alternatives to the current provision of post-compulsory education, which is very much focused on gaining 4 year academic qualifications Wolf, 2016), and provide viable pathways for those who do not expect, or cannot afford to go to university (Schoon \& LyonsAmos, 2016).

The study found significant associations between transition experiences and family socioeconomic resources as well as area characteristics, confirming the assumption of cumulative (dis)advantage and multiple deprivation in the transition to adulthood, i.e. less privileged young people are leaving education early or encounter more problems in establishing themselves in the labour market. Moreover, it matters where one lives. The opportunities and constraints in local labour markets are an independent risk factor shaping young people's lives. Yet, the findings also suggest that individuals are not passively exposed to the experience of disadvantage, and illustrate the heterogeneity of how young people respond to adverse socioeconomic conditions.

For example, the associations between socioeconomic resources and the four indicators of agency are very small (ranging from -.01 to -.08), confirming evidence reported in a meta-analytic study of associations between parental SES and selfesteem (Twenge \& Campbell, 2002), and suggesting potential self-protective mechanisms among adolescents that can reduce the effect of socioeconomic circumstances on the expression of individual agency. In particular, the findings suggest that agency indicators predict transition outcomes independent of structural constraints, i.e. they have a unique effect after controlling for family background, area effects, prior academic attainment, gender and ethnicity. Given the constraining forces in their immediate and wider social context, young people can to some extent actively steer the course of their lives. The study highlights the importance of conceptualising the role of the agent for a better understanding of diversity in youth transitions, rather than solely focusing on structures and socioeconomic resources (see also Hitlin \& Johnson, 2015). Moreover, there are interactive as well as domain-specific effects suggesting that young people select a specific pathway or niche that can offer them developmentally appropriate challenges through which they can experience competence and which enables them to feel satisfied about their lives.

Interestingly there is no significant difference in self-efficacy between those in higher education and those experiencing long-term NEET, potentially 
pointing to a possible 'dark' side of high competence beliefs, which for some can imply that they overestimate their abilities. This assumption is also supported by the significant interaction effect suggesting that high socioeconomic risk and high academic self-concepts are associated with an increased likelihood of experiencing NEET after some further education. We also found a significant interaction between high risk and goal certainty and the likelihood of entering employment after some further education, which might point to a turning point, where young people experiencing socioeconomic adversity were initially on track to higher education but might have changed their path after finding a promising full-time job. We furthermore find that high levels of school engagement are associated with a reduced likelihood of leaving school directly after compulsory schooling, to enter employment or prolonged periods of NEET, pointing to the significant role of engagement in the school context and underlying preferences for academic work as an influence on later life choices (Schoon, 2008). The findings suggest that within the available opportunities young people choose a pathway that fits with their preferences and which they see as achievable (Eccles et al., 1993). Although we find some interactive effects, cumulative risk effects and the independent effect model appear to be most appropriate in describing the inter-linkages between structure and agency shaping youth transitions.

Regarding the subjective evaluation of one's life at age 19/20 we find that both external (structural) and internal (individual) factors independently shape how one feels about one's life as a whole. Moreover, transition experiences fully mediate the influence of family socioeconomic resources on later life satisfaction, suggesting cumulative processes, and the amplification of prior difficulties or advantages. Yet, transition experiences do not fully mediate the influence of area characteristics and individual agency factors. Agency factors, especially goal certainty and school engagement, are significantly associated with life satisfaction after controlling for structural factors, gender, ethnicity, transition experiences, prior academic attainment and lifesatisfaction. Forethought and self-directedness are independent predictors of later life satisfaction, pointing to their role in shaping one's life course transitions as well as one's outlook on life.
There are multiple pathways to a successful transition, defying the notion of polarisation or assumption of a 'right way'. Most satisfied with their lives are those in higher education as well as those who established themselves in the labour market either through vocational training or some further education, while those who experienced NEET were least satisfied. Moreover, life satisfaction is influenced by area characteristics and transition experiences, suggesting that it matters where one lives and how one's life is shaping up. Previous studies have shown that neighbourhood effects are strongest during early childhood and late adolescence (Brooks-Gunn, Duncan \& Aber, 1997). This study confirms the importance of area deprivation for young adults and points to local opportunities, and potentially also collective socialisation (Ainsworth, 2002; loannides \& Loury, 2004), which influence the type of role models a young person is exposed to outside the home. The explained variance in our model is however low, and other factors and processes are likely to also play a role in shaping the subjective evaluation of one's life.

In interpreting the findings a number of limitations have to be considered. Like in all longitudinal studies we are faced with the problem of missingness in response. We checked the robustness of findings using multiple imputations (Mi-command in STATA), which confirmed the stability of the solution. We also had to make do with the information available in the data set. For example, some of our indicators of agency and the measures of life satisfaction are based on single items, which are less stable than multi-item scales. However, single-item assessments of education aspirations are widely used in large-scale surveys, suggesting satisfactory face validity (Sewell \& Hauser, 1993; Schulenberg \& Schoon, 2012), as are single item measures of life satisfaction (Lucas \& Donnellan, 2012). The correlations between our two indicators of subjective evaluation of one's life assessed during early adolescence and young adulthood are low, suggesting that either the measures tap into different aspects, or that there is considerable change in how young people evaluate their lives at different stages of the life course. Future research is needed to clarify this relationship further. Moreover, our study observes only a short period in the transition to employment, and changes in transitions at a later time point are very likely. Yet, we focus on a crucial period in the lives of young 
people when major decisions about which path to follow are made. However, our findings might be unique to the English context, reflecting its liberal regulation of school-to-work transitions and the impact of the 2008 recession on education and employment opportunities of young people. Future studies have to assess if the established patterns also apply in other countries, characterised by different transition regimes and economic circumstances. The role of gender and ethnicity, which showed highly significant associations with transition experiences as well as adult life satisfaction, also has to be studied in more detail in future studies.

Despite these limitations this study illustrates the fruitfulness of combining assumptions regarding school-to-work transitions from different disciplines and of examining interactions between person and environment (Schoon, 2015b). The socio-ecological model of agency enables us to gain a better insight into the processes underlying diverse youth transitions. We show that transition experiences are influenced by both socioeconomic and psycho-social resources and we have gained a better understanding of the interplay between structure and agency. Young people from less privileged background are less likely to participate in higher education. Yet, young people do not passively follow a pre-determined alternative of college or nothing, and given that constraints are not overpowering, can create alternative sustainable pathways. They are able to navigate their lives by balancing the resources available to them. The socio-ecological model of agency enables us to a. show the association between structural factors and indicators of agency; b. identify processes linking socioeconomic resources in the proximal and wider context to the timing and sequencing of transitions, taking into account agency factors; and c. illustrate how agency indicators can steer the direction of a pathway that corresponds to one's preferences, intentions, and self-concepts independently or in interaction with structural constraints. Whether this path will continue to fit one's preferences, intentions, and forethoughts remains to be seen, as both socioeconomic and psycho-social resources can change over time, introducing new opportunities and challenges.

\section{Acknowledgements}

Work for this study is supported by the Wissenschaftszentrum Berlin (WZB) and Grant Number ES/J019658/1 awarded to Ingrid Schoon from the British Economic and Social Research Council (ESRC) for the Centre for Learning and Life-chances in the Knowledge Economies (LLAKES, Phase II). Mark Lyons-Amos had been supported by the post-doctoral Fellowship program PATHWAYS to Adulthood, funded by the Jacobs Foundation.

\section{References}

Ainsworth, J. W. (2002). Why does it take a village? The mediation of neighborhood effects on educational achievement. Social Forces, 81(1), 117-152. https://doi.org/10.1353/sof.2002.0038

Arnett, J. J. (2000). Emerging Adulthood. A theory of development from the late teens to the late twenties. American Psychologist, 55(5), 469-480. https://doi.org/10.1037/0003-066X.55.5.469

Ashby, J. S., \& Schoon, I. (2010). Career success: The role of teenage career aspirations, ambition value and gender in predicting adult social status and earnings. Journal of Vocational Behavior, 77(3), 350-360. https://doi.org/10.1016/i.jvb.2010.06.006

Bandura, A. (2001). Social cognitive theory: An agentic perspective. Annual Review of Psychology, 52, 1-26. https://doi.org/10.1146/annurev.psych.52.1.1

Bandura, A. (2006). Toward a Psychology of Human Agency. Perspectives on Psychological Science, 1(2), 164180. https://doi.org/10.1111/j.1745-6916.2006.00011.x

Bandura, A., Barbaranelli, C., Caprara, G. V., \& Pastorelli, C. (2001). Self-efficacy beliefs as shapers of children's aspirations and career trajectories. Child Development, 72(1), 187-206.

https://doi.org/10.1111/1467-8624.00273 
BIS. (2013). Participation rates in higher education. Department for Business Innovation and Skills (BIS). https://www.gov.uk/government/uploads/system/uploads/attachment data/file/306138/13-p140HEIPR PUBLICATION 2011-12 2 .pdf

Blanden, J., Gregg, P., \& Macmillan, L. (2011). Intergenerational persistence in income and social class: The impact of within-group inequality. Retrieved from Bonn: Bourdieu, P., \& Passeron, J. (1977). Reproduction in Education, Society and Culture (Vol. 5). London: Sage Publications.

Breen, R., \& Goldthorpe, J. H. (2001). Class, mobility and merit - The experience of two British birth cohorts. European Sociological Review, 17(2), 81-101. https://doi.org/10.1093/esr/17.2.81

Breen, R., Luijkx, R., Muller, W., \& Pollak, R. (2009). Nonpersistent Inequality in Educational Attainment: Evidence from Eight European Countries. American Journal of Sociology, 114(5), 1475-1521. https://doi.org/10.1086/595951

Brzinsky-Fay, C., Kohler, U., \& Luniak, M. (2006). Sequence analysis with Stata. The Stata Journal, 4, 435-460.

Brooks-Gunn, J., Duncan, G. J., \& Aber, L. (1997). Neighborhood Poverty: Context and Consequences for Children. New York: Russel Sage Foundation.

Buchmann, M. C. (1989). The Script of Life in Modern Society: Entry Into Adulthood in a Changing World. Chicago: Chicago University Press.

Buchmann, M. C., \& Kriesi, I. (2011). Transition to Adulthood in Europe Annual Review of Sociology, 37, 481503. https://doi.org/10.1146/annurev-soc-081309-150212

Bukodi, E., \& Goldthorpe, J. H. (2013). Decomposing 'Social Origins': The Effects of Parents' Class, Status, and Education on the Educational Attainment of Their Children. European Sociological Review, 29(5), 1024-1039. https://doi.org/10.1093/esr/jcs079

Conger, R. D., Conger, K. J., \& Martin, M. J. (2010). Socioeconomic Status, Family Processes, and Individual Development. Journal of Marriage and the Family, 72(3), 685-704. https://doi.org/10.1111/j.17413737.2010.00725.x

Dannefer, D. (2003). Cumulative advantage/disadvantage and the life course: Cross fertilizing age and social science theory. The Journals of Gerontology, 58, 327-337. https://doi.org/10.1093/geronb/58.6.S327

Diener, E., Inglehart, R., \& Tay, L. (2013). Theory and Validity of Life Satisfaction Scales. Social Indicators Research, 112(3), 497-527. https://doi.org/10.1007/s11205-012-0076-y

DiPrete, T. A., \& Eirich, G. M. (2006). Cumulative advantage as a mechanism for inequality: A review of theoretical and empirical developments Annual Review of Sociology, Vol. 32, pp. 271-297). Palo Alto: Annual Reviews. https://doi.org/10.1146/annurev.soc.32.061604.123127

Duckworth, K., \& Schoon, I. (2012). Beating the odds: Exploring the aspects of social risk on young people's school-to-work transitions during recession in the UK. National Institute Economic Review, 222, 3851. https://doi.org/10.1177/002795011222200104

Duncan, G. J., \& Brooks-Gunn, J. (1997). Consequences of growing up poor. New York: Russell Sage Foundation Press.

Eccles, J. S. (2008). Agency and Structure in Human Development. Research in Human Development, 5(4), 231-243. https://doi.org/10.1080/15427600802493973

Eccles, J. S., Midgley, C., Wigfield, A., Buchanan, C. M., Reuman, D., Flanagan, C., \& Maciver, D. (1993). Development during adolescence - The impact of stage-environment fit on young adolescents experiences in schools and in families. American Psychologist, 48(2), 90-101. https://doi.org/10.1037//0003-066X.48.2.90

Eccles, J. S., \& Wigfield, A. (2002). Motivational beliefs, values, and goals. Annual Review of Psychology, 53, 109-132. https://doi.org/10.1146/annurev.psych.53.100901.135153

Elder, G. H. (1998). The life course as developmental theory. Child Development, 69(1), 1-12. https://doi.org/10.2307/1132065

Elder, G. H., \& Shanahan, M. J. (2007). The life course and human development The Handbook of Child Psychology. 6th edition. New York: Wiley.

Emirbayer, M., \& Mische, A. (1998). What is agency? American Journal of Sociology, 103(4), 962-1023. https://doi.org/10.1086/231294 
Erikson, R. (1984). Social class of men, women and families. Sociology-the Journal of the British Sociological Association, 18(4), 500-514. https://doi.org/10.1177/0038038584018004003

Erikson, R., \& Jonsson, J. O. (Eds.). (1996). Can education be equalized? The Swedish case in comparative perspective. Boulder, Colo. ; Oxford: Westview Press.

Fredricks, J. A., Blumenfeld, P. C., \& Paris, A. H. (2004). School engagement: Potential of the concept, state of evidence. Review of Educational Research, 74, 59-109. https://doi.org/10.3102/00346543074001059

Fuchs, S. (2001). Beyond agency. Sociological Theory, 19(1), 24-40. https://doi.org/10.1111/0735$\underline{2751.00126}$

Furlong, A., \& Cartmel, F. (1997). Young People and Social Change. Buckingham: Open University Press.

Galindo-Rueda, F., \& Vignoles, A. (2005). The Declining Relative Importance of Ability in Predicting Educational Attainment Journal of Human Resources, 40(2), 335-353.

Giddens, A. (1991). Modernity and self-identity: self and society in the late modern age. Cambridge: Polity Press.

Gregg, P., \& Wadsworth, J. (2001). Everything you ever wanted to know about measuring worklessness and polarization at the household level but were afraid to ask. Oxford Bulletin of Economics and Statistics, 63, 777-806. https://doi.org/10.1111/1468-0084.63.spe1.9

Guo, G., \& Harris, K. M. (2000). The mechanisms mediating the effects of poverty on children's intellectual development. Demography, 37(4), 431-447.

Heckhausen, J. (1999). Developmental regulation in adulthood: age-normative and sociostructural constraints as adaptive challenges. Cambridge: Cambridge University Press.

Heckhausen, J., \& Chang, E. S. (2009). Can ambition help overcome social Inequality in the transition to adulthood? Individual agency and societal opportunities in Germany and the United States. Research in Human Development, 6(4), 235-251. https://doi.org/10.1080/15427600903281244

Hitlin, S., \& Elder, G. H., Jr. (2007). Time, self, and the curiously abstract concept of agency. Sociological Theory, 25(2), 170-191. https://doi.org/10.1111/j.1467-9558.2007.00303.x

Hitlin, S., \& Johnson, M. K. (2015). Reconceptualizing Agency within the Life Course: The Power of Looking Ahead. American Journal of Sociology, 120(5), 1429-1472. https://doi.org/10.1086/681216

Ioannides, Y., \& Loury, L. (2004). Job information networks, neighbourhood effects and inequality. Journal of Economic Literature, 42(4), 1056-1093. https://doi.org/10.1257/0022051043004595

Jencks, C., \& Mayer, S. E. (1990). The social consequences of growing up in a poor neighbourhood. In L. E. J. Lynn \& M. G. H. McGeary (Eds.), Inner-city poverty in the United States (pp. 111-187). Washington, DC: National Academy Press.

Jones, G. (2002). The youth divide: diverging paths to adulthood. York: Joseph Rowntree Foundation.

Kerckhoff, A. C. (2001). Education and social stratification processes in comparative perspective. Sociology of Education, 3-18. https://doi.org/10.2307/2673250

Kins, E., \& Beyers, W. (2010). Failure to Launch, Failure to Achieve Criteria for Adulthood? Journal of Adolescent Research, 25(5), 743-777. https://doi.org/10.1177/0743558410371126

Lerner, R. M. (1996). Relative plasticity, integration, temporality, and diversity in human development: A developmental contextual perspective about theory, process, and method. Developmental Psychology, 32(4), 781-786. https://doi.org/10.1037/0012-1649.32.4.781

Loyal, S., \& Barnes, B. (2001). 'Agency' as a red hering. Philosophy of the Social Sciences, 31(4), 507-524. https://doi.org/10.1177/004839310103100403

Lucas, R. E., \& Donnellan, M. B. (2012). Estimating the Reliability of Single-Item Life Satisfaction Measures: Results from Four National Panel Studies. Social Indicators Research, 105(3), 323-331. https://doi.org/10.1007/s11205-011-9783-z

McLanahan, S. (2004). Diverging destinies: How children are faring under the second demographic transition. Demography, 41(4), 607-627. https://doi.org/10.1353/dem.2004.0033

McLeod, J. D., \& Lively, K. J. (2003). Social structure and personality. In J. DeLamater (Ed.), Handbook of Social Psychology (pp. 77-102). New York: kluwer.

Moore, K. A., Vandivere, S., \& Redd, Z. (2006). A sociodemographic risk index. Social Indicators Research, 75(1), 45-81. https://doi.org/10.1007/s11205-004-6398-7 
Mortimer, J. T. (2003). Working and growing up in America. Cambridge, Mass. ; London: Harvard University Press.

Murry, V. M., Berkel, C., Gaylord-Harden, N. K., Copeland-Linder, N., \& Nation, M. (2011). Neighborhood Poverty and Adolescent Development. Journal of Research on Adolescence, 21(1), 114-128. https://doi.org/10.1111/j.1532-7795.2010.00718.x

OECD. (2012). Education at a Glance 2012. Highlights.

Oishi, S. (2014). Socioecological Psychology. In S. T. Fiske (Ed.), Annual Review of Psychology, Vol 65 (Vol. 65, pp. 581-609).

ONS. (2013). Urban and Rural Area Definitions for Policy Purposes in England and Wales. Retrieved from Office of National Statistics.

https://www.gov.uk/government/uploads/system/uploads/attachment data/file/239477/RUC11me thodologypaperaug 28 Aug.pdf

Roberts, S. (2011). Beyond 'NEET' and 'tidy' pathways: considering the 'missing middle' of youth transition studies. Journal of Youth Studies 14, 21-39. https://doi.org/10.1080/13676261.2010.489604

Rutter, M. (1981). Stress, Coping and Development - Some Issues and Some Questions. Journal of Child Psychology and Psychiatry and Allied Disciplines, 22(4), 323-356. https://doi.org/10.1111/j.14697610.1981.tb00560.x

Salmela-Aro, K. (2009). Personal goals and well-being during critical life transitions: The four C's-Channelling, choice, co-agency and compensation. Advances in Life Course Research, 14(1-2), 63-73. https://doi.org/10.1016/j.alcr.2009.03.003

Scarpetta, S., Sonnet, A., \& Manfredi, T. (2010). Rising youth unemployment during the crisis: How to prevent negative long-term consequences on a generation? Retrieved from Paris:

Schoon, I. (2006). Risk and Resilience: Adaptations in Changing Times Cambridge: Cambridge University Press.

Schoon, I. (2007). Adaptations to changing times: Agency in context. International Journal of Psychology, 42(2), 94-101. https://doi.org/10.1080/00207590600991252

Schoon, I. (2008). A transgenerational model of status attainment: The potential mediating role of school motivation and education. National Institute Economic Review, 205, 72-82. https://doi.org/10.1177/0027950108096590

Schoon, I. (2014). Parental worklessness and the experience of NEET among their offspring. Evidence from the Longitudinal Study of Young People in England (LSYPE). Longitudinal and Life Course Studies, 6(6), 129-150. https://doi.org/10.14301/llcs.v5i2.279

Schoon, I. (2015a). Diverse pathways: Rethinking the transition to adulthood. In P. R. Amato, A. Booth, S. McHale, \& J. Van Hook (Eds.), Families in an era of increasing inequality. Diverging destinies (pp. 115136). London: Springer. https://doi.org/10.1007/978-3-319-08308-7 9

Schoon, I. (2015b). Let's work together: Towards interdisciplinary collaboration. Research in Human Development 12, 350-355. https://doi.org/10.1080/15427609.2015.1068050

Schoon, I. and Lyons-Amos, M. (2016). Diverse pathways in becoming an adult: the role of structure, agency and context. Research in Social Stratification and Mobility. ISSN 02765624. http://www.sciencedirect.com/science/article/pii/S0276562416300178

Schoon, I., \& Silbereisen, K. R. (Eds.). (2009). Transitions from School to Work: Globalisation, Individualisation, and Patterns of Diversity. New York Cambridge University Press.

Schulenberg, J. E., Bryant, A. L., \& O'Malley, P. M. (2004). Taking hold of some kind of life: How developmental tasks relate to trajectories of well-being during the transition to adulthood. Development and Psychopathology, 16(4), 1119-1140. https://doi.org/10.1017/S0954579404040167

Schulenberg, J. E., \& Schoon, I. (2012). The transition to adulthood in the UK, the US, and Finland: Differential social role pathways, their predictors and correlates. Longitudinal and Life Course Studies, 3(2), 164-172.

Settersten, J., R. A. (2007). The new landscape of adult life: Road maps, signposts, and speed lines Research in Human Development, 4, 239-252. https://doi.org/10.1080/15427600701663098 
Settersten, R. A., Furstenberg, F. F., \& Rumbaut, R. G. (2005). On the frontier of adulthood: Theory, research, and public policy. Chicago, III. ; London: University of Chicago Press. https://doi.org/10.7208/chicago/9780226748924.001.0001

Sewell, W. H., \& Hauser, R. M. (1993). A review of the Wisconsin Longitudinal Study of Social and Psychologocial Factors in Aspirations and Achievements 1963-1993. University of Wisconsin-Adison, Center for Demography and Ecology: CDE Working Paper No.92-01.

Shanahan, M. J. (2000). Pathways to adulthood in changing societies: Variability and mechanisms in life course perspective. Annual Review of Sociology, 26, 667-692. https://doi.org/10.1146/annurev.soc.26.1.667

Shavit, Y., Arum, R., \& Gamoran, A. (2007). Stratification in higher education: A comparative study. Stanford: Stanford University Press.

Twenge, J. M., \& Campbell, W. K. (2001). Age and birth cohort differences in self-esteem: A cross-temporal meta-analysis. Personality and Social Psychology Review, 5(4), 321-344. https://doi.org/10.1207/S15327957PSPR0504 3

Wolf, A. (2016). Remaking tertiary education: can we create a system that is fair and fit for purpose? Retrieved from: http://epi.org.uk/wp-content/uploads/2016/11/remaking-tertiary-educationweb.pdf

\section{Endnotes}

' We focus on the opportunity structures associated with socio-economic disadvantage, not potential cultural explanations associated with patterns of behaviours, beliefs or values that are transmitted through socialisation.

ii A Key Stage is a stage of the state education system in England, Wales and Northern Ireland. Key Stage 2 reflects attainment at the later stage of primary education, often known as junior schools. 